\title{
The Effectiveness of Fear of Leprosy As a Mediator of The Relationship Between Resilience, Coping Resources, and Coping: A Correlation Study Through The Structural Equation Model In Patients With Leprosy
}

\section{Cita Rosita Sigit Prakoeswa \\ Airlangga University \\ Medhi Denisa Alinda \\ Airlangga University \\ Bagus Haryo Kusumaputra \\ Airlangga University}

Abd. Nasir

Airlangga University

Ah Yusuf

Airlangga University

Muhammad Yulianto Listiawan ( $\sim$ yuliantowawan@yahoo.com )

Airlangga University

\section{Research Article}

Keywords: Resilience, Coping Resources, coping, fear, leprosy disability

Posted Date: December 29th, 2021

DOI: https://doi.org/10.21203/rs.3.rs-1159634/v1

License: (c) (i) This work is licensed under a Creative Commons Attribution 4.0 International License. Read Full License 


\section{Abstract}

Background: Strengthening the argument for better problem solving can reduce excessive worry, so as to reduce fear due to leprosy disability, because the impact arising from leprosy disability can affect the chosen coping strategy.

Methods: The purpose of this study was to test the model of the relationship between resilience, coping resources, and coping through structural equation modeling to identify the role of disability fear as a mediator. The leprosy disability fear scale, coping resources scale, and coping scale have been used to collect data, with 125 participants involved in this study through convenience sampling, consisting of women (33.60\%), men $66.40 \%$. Structural equation model is used to test through cross-sectional design.

Results: The results of the study report that there is a negative relationship between coping resources and fear of leprosy disability, and it is known that there is a positive relationship with coping. Meanwhile, The test results showed a negative relationship between resilience and fear of leprosy disability, and a positive relationship with coping. Furthermore, to coping, fear of leprosy disability shows a negative relationship.

Conclusion: Coping in seeking health assistance is strongly influenced by resilience and coping resources, both directly and indirectly through the mediator of fear of leprosy disability. As a result, in seeking health assistance, individuals who have strong self-defense and have extensive coping resources, have adaptive coping, thereby reducing the fear of leprosy disability, and thus can maintain adaptive coping during the leprosy healing process.

\section{Introduction}

Permanent disability is a serious threat to people with leprosy because it can occur before, during, and after treatment. Besides, second-degree disability has been experienced by more than 10,000 of the population detected or, $5 \%$ more than the number of cases detected by the end of $2019^{1}$. In Indonesia, the government has implemented many steps to minimize leprosy defects such as disability prevention checks, early detection of leprosy reactions, and a tapering of prednisone program for leprosy patients who have leprosy reactions ${ }^{2}$. Meanwhile, until now there is still no drug that is able to prevent and stop the attack of leprosy reactions, and it is still difficult to control the factors that cause leprosy reactions as a trigger for leprosy disability ${ }^{3}$. Therefore, this situation has caused psycho-emotional effects which is very scary because the impact shows signs of severity that are very clear and scary on the skin of the face and other body parts, such as erythematous subcutaneous nodules ${ }^{4}$, as a result of acute inflammatory episodes of the chronic course of Mycobacterium leprae ${ }^{5}$, and this is always connected with coping in seeking health assistance ${ }^{6}$.

Avoiding the effects of psycho-emotional responses is a very important effort related to leprosy disability. Research conducted in India has shown symptoms of depression, anxiety, and increased stress in people with leprosy with disabilities ${ }^{7,8}$. Besides, it can also cause anxiety and restlessness among some leprosy individuals 9 . This situation is caused by a feeling of fear of stigma from their environment and themselves ${ }^{10,11}$. Moreover, feelings of worry such as not getting a decent job, being far from a decent life ${ }^{12,13}$, and afraid of being left by a partner or not getting a partner ${ }^{14}$, can weigh heavily on their minds, and feeling humiliated or feeling worthless further adds to their suffering ${ }^{15}$ 


\section{Resilience as a factor to prevent psycho-emotional disorders}

Resilience is an element of positive psychology and is very effectively used as a protector during psychoemotional disorders. In fact, resilience is used to speed up recovery from stressful life events and has a powerful ability to restore feelings of happiness (Loh et al., 2014). In other words, resilience can be interpreted as an individual's resilience to remain determined during situational crisis conditions ${ }^{17}$. As long as disability is carried over into everyday life by lepers, individual resilience may decrease while efforts to expand coping resources may also be affected (Sadati et al. 2020), and then difficult situations become a part of his life ${ }^{18}$

Thus, resilience has a very significant contribution in overcoming fear, panic, anxiety, and stress due to disability caused by leprosy. The results of studies report that maximum involvement of resilience attributes for effective stress management strongly supports this view (Steinhardt dan Dolbier 2008). In addition, resilience is positively correlated with better coping ${ }^{19}$, motivation to seek the help of health ${ }^{20}$ consistent with the use of definitive health facilities for patients with chronic diseases, as well as problems that cause stress ${ }^{21,22}$. All of which are indicators of better health- seeking behavior. Furthermore, it has also been argued that resilience protects not only from mental health aspects, but also from physical, and social health aspects ${ }^{23,24}$. As a result, strong resilience is most likely associated with a lower fear of leprosy disability.

\section{Coping resources as a protective factor in preventing fear of leprosy disability}

Coping resources as an important attribute of positive psychology can be proven as an important instrument to protect various psychosocial problems so that it is very effective in reducing the fear of leprosy disability. Coping resources are also always associated with what individuals have when they develop coping strategies, and this is always related to the availability of personal and environmental resources ${ }^{25}$. In other words, coping resources can be seen from the individual's ability to remain alert in facing difficult situations ${ }^{26}$. As long as the disability of leprosy becomes a burden in a leper's personal life, coping resources may be underutilized, and maladaptive coping becomes the worst choice for the best course of action at that time.

The emergence of coping resources can be considered as an important instrument to protect against fear, panic, anxiety, and stress ${ }^{27}$. This also applies to psycho-emotional disorders due to leprosy disability. The research findings which report that the use of coping resources is very helpful in creating effective fear, anxiety, and stress coping strategies, strongly support the results of this study ${ }^{28}$. Besides, coping resources have a positive relationship with variables such as adjustment to stressful situations ${ }^{29}$ and life satisfaction ${ }^{30}$. All of which are good indicators of psychological well-being. Furthermore, it has also been found that coping resources not only protect a person against panic attacks but can also be used as an assessment of certain situations so that he can predict coping behavior ${ }^{31}$. As a result, strong coping resources are most likely associated with lower feelings of stress due to leprosy disability.

\section{Adaptation coping of help-seeking behavior}

Coping is the basic concept of how a person acts to overcome the problems he faces. Against chronic diseases, coping takes place continuously and changes according to needs until finding adaptive coping to get effectiveness ${ }^{32}$. Meanwhile, with advances in technology and early detection, there is an increasing number of individuals with chronic diseases living the long term, and that means that more people are living longer with 
chronic conditions ${ }^{33}$, so the need for adjustment is important ${ }^{34}$, primarily adjustment to psychological conditions 35. There is a great effort to integrate chronic illness into the context of their lives and participate in personally meaningful lives, despite limited resources ${ }^{36}$, thus requiring self-management to reduce their psychological stress 37 , because they are indicated for the growth of post-traumatic syndrome disease ${ }^{38}$. Identifying resources to deal with problems in chronic illness becomes very important to be applied in avoiding stress and loneliness ${ }^{39}$. Recent findings support control-based coping models that include primary control or active coping (attempts to act on the source of one's stress or emotion), secondary control or accommodative coping (attempts to adapt to the source of stress), and passive coping or disengagement (attempts to avoid or deny stressors) ${ }^{40}$. Especially in chronic disease problems such as the disability in leprosy, the need for problem-solving fluctuates along with the development of the disease, so it requires adaptive coping efforts, and this is connected with coping resources 41 , and resilience ${ }^{19}$, because this can provide direction and purpose for the achievement of effective coping.

\section{Current study}

Since the discovery of leprosy disability, the burden experienced by individuals exceeds the tasks that must be carried out for healing the disease, because their prejudice is very bad about themselves and what they experience seems to be felt by others ${ }^{42}$, and at that time, stigma and discrimination became part of their personal lives ${ }^{43}$. Therefore, withdrawing and not being actively involved in socializing in society is the best choice to protect and maintain their self-concept ${ }^{44}$. These measures have a negative impact on health care workers' treatment and monitoring programs ${ }^{45,46}$. That is why it is so important to determine the factors that protect their health-seeking behavior and their daily functioning.

Focusing on one's strengths from maladaptive coping in people with leprosy, behavior seeking health assistance in terms of protection and prevention is the key to prevent and treat disability due to leprosy ${ }^{47}$. Therefore, understanding their coping in seeking health assistance and focusing on individual strengths are important factors in dealing with disability due to leprosy. In this context, resilience and coping resources are protective factors of coping that prevent stress and other emotional responses due to leprosy disability, and this will play an important role in avoiding the negative effects of fear of leprosy disability. Studies that have evaluated the disability effects of leprosy from the perspective of seeking health assistance have often focused on the maladaptive aspect ${ }^{48}$. However, focusing on coping, resilience, and coping resources, may be more effective in developing adaptive coping ${ }^{49}$. In this regard, analyzing the relationship between stress on leprosy disability and coping (which is a strength in seeking medical help), can provide important information about how a person can become more adaptive during seeking health assistance for their cure.

Consequently, the protective factors associated with overcoming stress on leprosy disability must be considered, in addition to psycho-emotional problems. Besides, other areas that require analysis are related to what protective factors are and what might happen if an individual's strength weakens. Regarding the stress of leprosy disability, previous studies have not examined resilience, coping resources as protection, and coping as an indicator of seeking adaptive health assistance. Therefore, the role of stress on leprosy disability as a mediator between resilience and coping resources was tested in this study. As a result, two hypotheses (Hs) were formulated based on the literature above: $(\mathrm{H} 1)$ the relationship between resilience and coping will be mediated by fear of leprosy disability, (H2) the relationship between coping resources and coping will be mediated by fear of leprosy disability.

\section{Methods}




\section{Participants and Procedure}

Data were obtained from a cross-sectional study using convenience sampling in which data collection was carried out between March 2021 to June 2021. The sample was leprosy patients who were treated at the Leprosy Polyclinic at Dr. Sutomo General Hospital Surabaya, including 42 (33.60\%) women and $83(66.40 \%)$ men. The mean age of participants was > 15 years as many as $122(97.60 \%),<15$ years as many as $3(2.40 \%)$, marital status of participants was married as many as 65 (52\%), not married as many as 60 (48\%), employment status was working as many as $65(52 \%)$ and not working as many as $60(48 \%)$. The number of participants who experienced leprosy reactions was once as many as 63 (50.40\%), twice as many as $14(11.20 \%)$, three times as many as 12 (9.60\%), four times as many as 15 (12.00\%), five times as many as $12(9.60 \%)$ and more than 5 times as many as 9 (7.20\%), and in full, it can be seen in Table 1. Questionnaires were given to people with leprosy in a paper and pencil-based format in Indonesian. Informed consent was obtained from the participants after the researchers provided brief information about the study. Participants completed all questionnaires (four selfreports) anonymously to avoid response bias so that each participant could not be identified. Participants are welcome to withdraw from the study at any time they wish if they do not wish to participate. On average, each participant took about 20 to 30 minutes to fill out the questionnaire. 
Table 1

Results of the Analysis of Respondents Characteristics

\begin{tabular}{|c|c|c|c|}
\hline Characteristics & Category & Frequency & Persentase (\%) \\
\hline \multirow[t]{2}{*}{ Gender } & Men & 83 & 66,40 \\
\hline & Women & 42 & 33,60 \\
\hline \multirow[t]{2}{*}{ Age } & $<15$ Years & 3 & 2,40 \\
\hline & $>15$ Years & 122 & 97,60 \\
\hline \multirow[t]{2}{*}{ Marital status } & Married & 65 & 52,00 \\
\hline & Not Household & 60 & 48,00 \\
\hline \multirow[t]{5}{*}{ Level of education } & No school & 6 & 4,80 \\
\hline & Primary school & 9 & 7,20 \\
\hline & Junior high school & 23 & 18,40 \\
\hline & Senior High School & 57 & 45,60 \\
\hline & Diploma / College & 30 & 24,00 \\
\hline \multirow[t]{2}{*}{ Employment status } & Employed & 65 & 52,00 \\
\hline & Unemployed & 60 & 48,00 \\
\hline \multirow[t]{2}{*}{ Types of Leprosy } & $\mathrm{MB}$ & 47 & 37,60 \\
\hline & PB & 78 & 62,40 \\
\hline \multirow[t]{4}{*}{ Sick time } & $<1$ Years & 45 & 36,00 \\
\hline & 1 Years & 66 & 52,80 \\
\hline & 2 Years & 2 & 1,60 \\
\hline & $\geq 4$ Years & 12 & 9,60 \\
\hline \multirow[t]{6}{*}{ Leprosy Reaction } & 1 Time & 63 & 50,40 \\
\hline & 2 Time & 14 & 11,20 \\
\hline & 3 Time & 12 & 9,60 \\
\hline & 4 Time & 15 & 12,00 \\
\hline & 5 Time & 12 & 9,60 \\
\hline & > 5 Time & 9 & 7,20 \\
\hline \multirow[t]{2}{*}{ Leprosy Family } & Yes & 6 & 4,8 \\
\hline & No & 119 & 95,2 \\
\hline
\end{tabular}

Data analysis 
This study was not preregistered. Descriptive statistics, convergent and discriminant validity, and internal reliability were examined. Then, bivariate correlation (Pearson's correlation coefficient) was calculated. The researchers also analyzed the mediation model based on the two-step SEM (measurement and structural model) approach recommended by Anderson \& Gerbing (1988). The relationship between resilience, coping resources, coping and fear of leprosy disability was tested using cross-sectional analysis through descriptive statistical analysis (mean, standard deviation) using IBMSPSS Statistics version 20. The role of fear of leprosy disability as a mediator was tested using a two-step equation modeling analysis. Hu \& Bentler (1999) suggest evaluating the overall fit of the model to the data using the data fit index. According to the advice of ${ }^{52}$, that the evaluation of the outer model has been carried out using structural equation modeling through construct evaluation by calculating convergent validity which involves an assessment of the loading factor and Average Variance Extracted (AVE) and evaluation of construct reliability by calculating the value of Cronbach's Alpha and the value of composite reliability. Evaluation of the structural model based on stages was also carried out by evaluating the goodness of fit, including the coefficient of determination by calculating the R Square value, 1 - R Square, and the total $R$ Square value. Besides, the value of predictive relevance was also analyzed by calculating the value of SSO, SSE, and Predictive Relevance (Q2) values as suggested by ${ }^{53}$. Hypothesis testing was conducted to determine the relationship between resilience variables, coping resources, fear of leprosy disability, and coping.

\section{Results}

Descriptive statistics of variables

Table 2 shows that respondents' perceptions of the variables have a good average and standard deviation, including the resilience variable in which the mean and standard deviation is 3.1439-1.09691. Besides the results of coping resources variables with cognitive dimensions is $2.8053-0.71246$, social is $2.8128-0.71335$, emotional $2.7560-0.73949$, spiritual is $2.7360-0.74210$, and physical is $2.7880-0.74396$. Respondents' perceptions of the fear of leprosy disability variable have an average and standard deviation of $2.6574-0.51368$, while the coping variable on the dimensions of overcoming problems is $2.9758-0.87845$, and avoiding problems is $2.7697-0.84960$. 
Table 2

Description of Research Variables

\begin{tabular}{|lllll|}
\hline Variable & Dimension & Mean & Std. Deviation & Information \\
\hline Resillience & & 3,1439 & 1,09691 & pretty good value \\
\hline Coping Resources & Cognitive & 2,8053 & 0,71246 & good value \\
\cline { 2 - 5 } & Social & 2,8128 & 0,71335 & good value \\
\cline { 2 - 5 } & Emotional & 2,7560 & 0,73949 & good value \\
\cline { 2 - 5 } & Spritual & 2,7360 & 0,74210 & good value \\
\cline { 2 - 5 } Fear of leprosy disability & Physical & 2,7880 & 0,74396 & good value \\
\hline Coping & Solving problem & 2,9758 & 0,87845 & good value \\
\cline { 2 - 5 } & Avoid Trouble & 2,7697 & 0,84960 & good value \\
\cline { 2 - 5 }
\end{tabular}

Structural Equation Modeling

\section{Outer Model Evaluation}

The outer model evaluation consists of construct validity evaluation and construct reliability evaluation.

Evaluation of construct validity was done by calculating the value of convergent validity which is represented by the value of loading factor and Average Variance Extracted (AVE), and it has been obtained that the value of loading factor of resilience is between $(0.899-0.943)>0.05$, with the Average Variance Extracted (AVE) value of $(0.859)>0.05$, which can be concluded that the resilience variable is good so it is valid to measure the variable. Besides, the coping resources loading factor value is between $(0.960-0.981)>0.5$, with the Average Variance Extracted (AVE) of $(0.938)>0.05$, which can be concluded that the coping resources variable is good so it is valid to measure the variable. Meanwhile, the loading factor value of the fear of leprosy disability is $(1,000)>0.05$, with the Average Variance Extracted (AVE) value of $(1,000)>0.05$ which can be concluded that the variable fear of leprosy disability is good so it is valid to measure the variable. Besides, measurements have also been made on the loading factor value of the coping variable, which is between $(0.970-0.974>0.5$, with the Average Variance Extracted (AVE) value of $(0.944)>0.05$ which can be concluded that the coping variable is good so that it is valid to measure the variable. While the indicator that gives the biggest contribution in measuring resilience is BRS 1 (0.943), coping resources are social (0.981), and coping is problem-solving (0.974). This is evidenced by the value of the loading of the indicator factors in each of the highest latent variables. Meanwhile, the results of the evaluation of discriminant validity, which are based on the evaluation results of the cross-loading of discriminant validity test, reported that overall, the indicators of all variables (bold font) produce a loading value that is greater than the loading value on other variables. This can be concluded that from the discriminant validity test, each indicator is able to measure the latent variable that corresponds to the indicator.

Besides, the evaluation results of the construct validity test show that the Cronbach's Alpha value of coping resources is 0.983 , resilience is 0.967 , fear of leprosy disability is 1,000 , and coping is $0.941>0.6$. Furthermore, the value of composite reliability from coping resources is 0.987 , resilience is 0.973 , fear of leprosy disability is 1,000 , and coping is $(0.971)>0.7$. The detail can be seen in Table 3 . 
Table 3

Results of Testing Discriminant Validity Cross Loading, Convergent Validity and construct Validity

\begin{tabular}{|c|c|c|c|c|c|c|c|c|}
\hline & Validitas D & kriminan $\mathrm{Crc}$ & s Laoding & & $\begin{array}{l}\text { Converge } \\
\text { Validity }\end{array}$ & & Construct & lidity \\
\hline & $\begin{array}{l}\text { Coping } \\
\text { Resources }\end{array}$ & Resillience & $\begin{array}{l}\text { Fear of } \\
\text { leprosy } \\
\text { disability }\end{array}$ & Coping & $\begin{array}{l}\text { Loading } \\
\text { Faktor }\end{array}$ & AVE & $\begin{array}{l}\text { Cronbach's } \\
\text { Alpha }\end{array}$ & $\begin{array}{l}\text { Composite } \\
\text { Reliability }\end{array}$ \\
\hline Cognitive & 0,964 & 0,866 & $-0,856$ & 0,860 & 0,964 & 0,938 & 0,983 & 0,987 \\
\hline Social & 0,981 & 0,875 & $-0,884$ & 0,874 & 0,981 & & & \\
\hline Emotional & 0,972 & 0,870 & $-0,868$ & 0,845 & 0,972 & & & \\
\hline Spritual & 0,960 & 0,825 & $-0,824$ & 0,814 & 0,960 & & & \\
\hline Physical & 0,966 & 0,830 & $-0,852$ & 0,824 & 0,966 & & & \\
\hline BRS 1 & 0,836 & 0,943 & $-0,840$ & 0,846 & 0,943 & 0,859 & 0,967 & 0,973 \\
\hline BRS 2 & 0,844 & 0,938 & $-0,829$ & 0,854 & 0,938 & & & \\
\hline BRS 3 & 0,837 & 0,920 & $-0,829$ & 0,843 & 0,920 & & & \\
\hline BRS 4 & 0,830 & 0,935 & $-0,829$ & 0,849 & 0,935 & & & \\
\hline BRS 5 & 0,786 & 0,924 & $-0,822$ & 0,832 & 0,924 & & & \\
\hline BRS 6 & 0,762 & 0,899 & $-0,805$ & 0,759 & 0,899 & & & \\
\hline $\begin{array}{l}\text { Fear of } \\
\text { leprosy } \\
\text { disability }\end{array}$ & $-0,885$ & $-0,891$ & 1,000 & $-0,884$ & 1,000 & 1,000 & 1,000 & 1,000 \\
\hline $\begin{array}{l}\text { Problem } \\
\text { Solving }\end{array}$ & 0,877 & 0,908 & $-0,890$ & 0,974 & 0,974 & 0,944 & 0,941 & 0,971 \\
\hline $\begin{array}{l}\text { Avoid } \\
\text { Trouble }\end{array}$ & 0,814 & 0,833 & $-0,827$ & 0,970 & 0,970 & & & \\
\hline
\end{tabular}

\section{Inner Models Evaluation}

Evaluation of the structural model, based on the goodness of fit of the evaluation stage, consists of the coefficient of determination, predictive relevance, and the value of hypothesis testing. The results showed that the value of the coefficient of determination (R2) on the variable fear of leprosy disability is R-square (0.849) and 1 - R Square (0.151). While for the value of coping variable, the value of $R$ Square is 0.839 and $1-R$ Square is 0.161 with a total $\mathrm{R}$ Square value that shows the number of 0.976 , which indicates that the relationship between resilience and coping resources is either directly or indirectly through fear of leprosy disability to coping of 0.976 . Predictive Relevance (Q2) values for the variable fear of leprosy disability have also been identified, including the value of SSO (125.00), SSE (22.884), and $Q^{2}$ (=1-SSE/SSO) with a value of $(0.817)>0$ in which the value of the coping variable shows the results of SSO $(250,000)$, SSE $(62.543)$ and $Q^{2}(=1$-SSE/SSO) with a value of $(0.750)>0$, so it can be said that this model is good enough. The detail can be seen in Table 4. 
Table 4

Predictive Relevance and Coefficient of Determination Results $\left(R^{2}\right)$

\begin{tabular}{|c|c|c|c|c|c|c|}
\hline \multirow[t]{2}{*}{ Dependent Variable } & \multicolumn{3}{|c|}{ Predictive Relevance $\left(\mathrm{Q}^{2}\right)$} & \multicolumn{3}{|c|}{ Coefficient of Determination $\left(\mathrm{R}^{2}\right)$} \\
\hline & sso & SSE & $\begin{array}{l}Q^{2}(=1- \\
\text { SSE/SSO) }\end{array}$ & $\begin{array}{l}\mathrm{R} \\
\text { Square }\end{array}$ & $\begin{array}{l}1-R \\
\text { Square }\end{array}$ & $\begin{array}{l}\text { R Square } \\
\text { Total }\end{array}$ \\
\hline Leprosy Stress & 125,000 & 22,884 & 0,817 & 0,849 & 0,151 & 0,976 \\
\hline $\begin{array}{l}\text { Psychological Well- } \\
\text { being }\end{array}$ & 250,000 & 62,543 & 0,750 & 0,839 & 0,161 & \\
\hline
\end{tabular}

Based on the results of hypothesis testing, it has been reported that coping resources and resilience have a negative correlation with fear of leprosy disability as indicated by the coefficient value of coping resources on fear of leprosy disability which is $(-0.447)$ and is supported by the value of T statistics $(5.973)>1.96$, and p-value $(0.000)<0.05$. While the coefficient value of resilience to fear of leprosy disability is $(-0.497)$, and is supported by the value of $T$ statistics $(6.534)>1.96$, with a p-value of $0.000<0.05$. This shows that the ability to expand the identification of coping resources and increase resilience can be used as a buffer for psychological problems, mainly to reduce the fear of leprosy disability. In other words, the ability to expand the identification of coping resources and resilience strengths that meet the elements of the scope of positive psychology can be used as another alternative to reduce the fear of leprosy disability.

Furthermore, it is known that coping resources and resilience have a positive contribution to coping with the acquisition of the coefficient value of the relationship between coping resources and coping of 0.226 , T statistic of $(2,000)>1.96$, and $p$-value of $(0.000)<0.05$. Besides, the coefficient of the relationship between resilience and coping is (0.428), T statistics value is $(3.400)>1.96$, and $p$-value is $0.000<0.046$. Meanwhile, there is a negative relationship between fear of leprosy disability and coping as indicated by the coefficient value of fear of leprosy disability on coping of -0.303 , T statistic of $(3.534)>1.96$, and $p$-value of $(0.000)<0,05$. This indicates that the ability to expand the identification of coping resources and resilience can contribute to the achievement of adaptive coping for people with leprosy. In other words, the strength of resilience as a positive psychological attribute of psychological problems and the ability to expand coping resources can support and provide feeling happy despite psychological pressure due to suffering from leprosy. The detail has been shown in Table 5

Table 5

Hypothesis Testing Results

\begin{tabular}{|llll|}
\hline Influence & Coefficient & T Statistics (|O/STDEV|) & P Values \\
\hline Coping Resources -> Fear of Leprosy Disability & $-0,447$ & 5,973 & 0,000 \\
\hline Resillience -> Fear of Leprosy Disability & $-0,497$ & 6,534 & 0,000 \\
\hline Coping Resources -> Coping & 0,226 & 2,000 & 0,046 \\
\hline Resillience -> Coping & 0,428 & 3,400 & 0,001 \\
\hline Fear of Leprosy Disability -> Coping & $-0,303$ & 3,534 & 0,000 \\
\hline
\end{tabular}

\section{Discussion}


Stress due to leprosy disability causes feelings of depression and becomes a psychological burden for sufferers because the impact affects physical, psychological, and social conditions ${ }^{54}$. Furthermore, stress, which is defined as a demand to meet needs, is closely related to cognitive function and behavior ${ }^{55}$, because it is always related to adaptive functioning and this contributes to psychosocial problems ${ }^{56}$ and psycho-emotional ${ }^{57}$. On the other hand, resilience is a source of self-defense from various mental stresses ${ }^{58}$, as well as coping resources which are protective factors in preventing the development of negative judgments on psycho-emotional responses ${ }^{30}$, and this has a positive relationship with coping ${ }^{59,60}$. As a result, resilience and coping resources are considered as protective factors that can prevent mental health problems that may arise from stress due to leprosy disability to achieve adaptive coping. Therefore, this study examines the role of fear of leprosy disability as a mediator in the relationship between resilience, coping resources, and coping.

The first finding shows that fear of disability in leprosy partially mediates the relationship between resilience and coping, which supports $\mathrm{H} 1$. In other words, people who have high resilience, experience low fear of leprosy disability which ultimately has adaptive coping. As in endemic leprosy, the experience experienced during the disability of leprosy sufferers has caused a very high feeling of fear of leprosy disability because they are unable to maintain self-concept among some individuals ${ }^{61}$. Therefore, it requires a new positive psychological instrument to maintain mental stress. Besides, resilience becomes a buffer for people who want to defend themselves from all psychological stress, because it automatically activates positive emotions to overcome the stress ${ }^{62}$. Moreover, resilience also mediates a positive relationship between emotional intelligence and life satisfaction ${ }^{63}$. Counseling interventions, which are directed at developing individual resilience, have overall been effective in reducing psychological disorders ${ }^{64}$ and Post Traumatic Syndrom Disorder (PTSD) ${ }^{65}$. This is also very useful for lepers and their families ${ }^{66}$. On the other hand, resilience has a positive correlation with adaptive coping 64 and subjective well-being ${ }^{67}$, and life satisfaction ${ }^{68,69}$. So the findings here that the existence of resilience to develop mental health by reducing fear, can be said to be a feature similar to the findings of previous studies.

The second finding shows that the fear of disability in leprosy partially mediates the positive relationship between coping resources and coping that supports $\mathrm{H} 2$. For this assumption, that in preventing individuals from developing a fear of leprosy disability, having extensive cooping resources can develop adaptive coping in seeking health assistance. This is because of the disability that lepers always carry throughout their lives, giving them very heavy mental pressure ${ }^{70}$ and self stigmatization ${ }^{61}$. Also, the stigma and discrimination that they receive from their environment can add to their suffering ${ }^{11}$. Thus, an effective coping strategy is needed.

Cognitive therapy is given with the aim of expanding coping resources, reducing fear, especially in chronic diseases, in which the sufferer is expected to have adaptive coping ${ }^{71}$. The development of interventions to expand coping resources has also been shown to help individuals develop resilience ${ }^{64}$. Therefore, it can be said that expanding coping resources can help to overcome fear and anxiety about leprosy disability. This is in line with other studies that have reported a positive relationship between coping resources and adaptive coping ${ }^{72}$. Thus, the findings in this study are in line with the findings of previous studies. Through a positive psychological approach, strengthening resilience and expanding coping resources is a psychological strength, but not to treat psychological disorders, and developing psychological strength is an alternative pathway in protecting mental health ${ }^{73}$, because the effect has psychological flexibility, both directly and indirectly (mediated) to the application of adaptive coping ${ }^{74}$. 
Finally, the resilience and coping resources possessed by leprosy sufferers, with a low level of fear of leprosy disability as a mediator, may contribute to the application of adaptive coping. Therefore, with high strength of resilience and efforts to expand coping resources, it can prevent the fear of leprosy disability, and the assumption that these attributes can be used as a support for the application of coping in order to adapt to behavior to seek definitive health assistance seems feasible to be accepted. A positive psychological approach that involves elements of resilience and coping resources to overcome maladaptive coping is one of the effective psychological strengths, and the use of psychological strengths is a solution alternative to support the determination of effective coping strategies ${ }^{75}$. In fact, it has been shown that intervention programs that focus on positive psychology are very effective in reducing fear, which in turn is used as a mediator to determine adaptive coping ${ }^{76}$. And next, resilience ${ }^{77}$ and coping resources ${ }^{78}$ can be a buffer to support the selection of various alternative coping sources to achieve adaptive coping, and this strengthens the argumentation of the results of this study.

Thus, resilience and coping resources, with low fear of leprosy disability as a mediator, are proven to predict adaptive coping in seeking definitive health assistance. Therefore, resilience and coping resources that can prevent the fear of disability from leprosy can support roles, functions, and daily tasks, and the assumption may be true, that it can help in choosing the appropriate alternative coping sources and avoiding passive coping ${ }^{40}$.

\section{Conclusion}

Preparations to protect against psychological disorders in leprosy sufferers due to the threat of leprosy disability that occurs throughout their lives are very important to be given, because the impact of leprosy disability results in psychosocial problems in which its effects affect physical, psychological, and social conditions, and this is a trigger for the emergence of mal coping. -adaptive in seeking health assistance. In connection with this, the results of this study have identified that resilience and coping resources have a very significant role in the ability to solve problems constructively, and this is always associated with a decrease in fear of leprosy disability and adaptive coping in solving health problems. With the word times that individuals who have extensive coping resources and increased resilience, it is possible to use alternative flexible coping sources to overcome the fear of leprosy disability and maintain adaptive coping. Their experience of fear of leprosy can be handled adaptively on a practical level and as a result, they can use adaptive coping to achieve optimal healing for their disease.

\section{Declarations}

\section{Ackowledgement}

The author would like to thank Leprosy patiens and those around them, for sharing their experiences. We would also like to express our gratitude to the administrators at the institution who have assisted and supported this research.

\section{Funding}

This research did not receive any specific grant from funding agencies in the public, commercial, or not for- profit sectors.

\section{Availability of data and materials}


All authors state that this research is supported by valid data and data files have been uploaded to the Supplementary Materials for Review electronic box

\section{Ethical Approval}

The study procedure was in accordance with the Declaration of Helsinki and was approved by the Dr. Sutomo Surabaya Hospital Research Ethics Committee with the number: 0168/KEPK/III/2021. March 30, 2021. All participants gave informed consent in which they were informed that they could withdraw at any time from the study.

\section{Declaration of Conflicting Interests}

All authors critically revise the article, give final approval for the submission of the article, and agree to be responsible for all aspects of the work in ensuring that questions related to the accuracy or integrity of each part of the work are properly researched and resolved, and there are NO conflicts of interest

\section{Author Contributions}

All authors contributed to the study design. AN, MYL. developed the study concept. Testing and data collection were performed by MYL, CRSP. and MDA. Performed the data analysis and interpretation under the supervision of AN. BHK. drafted the paper, and AY. and CRSP. provided critical revisions. All authors approved the final version of the paper for submission."

\section{References}

1. WHO Global Report. Global leprosy update, 2018: moving towards a leprosyfree world. (2019).

2. Blok, D. J., Vlas, S. J. De \& Richardus, J. H. Global elimination of leprosy by 2020: are we on track? Parasit. Vectors (2020) doi:10.1186/s13071-015-1143-4.

3. Scollard, D. M. et al. Risk factors for leprosy reactions in three endemic countries. Am. J. Trop. Med. Hyg. 92, 108-114 (2015).

4. Kahawita, I. P., Walker, S. L. \& Lockwood, D. N. J. Leprosy type 1 reactions and erythema nodosum leprosum. An. Bras. Dermatol. 83, 75-82 (2008).

5. Nery, J. A. da C. et al. Compreender melhor o estado reacional tipo 1 para o diagnóstico e tratamento precoces: Uma forma de se evitar as incapacidades na hanseníase. An. Bras. Dermatol. 88, 787-792 (2013).

6. Matos, H. J. De, Blok, D. J., Vlas, S. J. De \& Richardus, J. H. Leprosy New Case Detection Trends and the Future Effect of Preventive Interventions in Pará State, Brazil : A Modelling Study. 1-10 (2016) doi:10.1371/journal.pntd.0004507.

7. Jatimi, A., Yusuf, A. \& Andayani, S. R. D. Leprosy Resilience with Disabilities Due to Illness: A Qualitative Study. Indones. Nurs. J. Educ. Clin. 5, (2020).

8. Singh, G. P., Mohan, V., Mahajan, B. \& Jindal, K. Psychiatric morbidity among inmates of leprosy homes. Indian J. Psychol. Med. 35, 335 (2013).

9. Govindharaj, P., Srinivasan, S. \& Darlong, J. Perception toward the Disease of the People Affected by Leprosy. 247-250 (2018) doi:10.4103/ijmy.ijmy. 
10. Lusli, M. et al. Dealing with stigma: Experiences of persons affected by disabilities and leprosy. Biomed Res. Int. 2015, (2015).

11. van Brakel, W. H. et al. Disability in people affected by leprosy: the role of impairment, activity, social participation, stigma and discrimination. Glob. Health Action 5, 1-11 (2012).

12. Castro, C. M., Erazo, L. \& Gunturiz, M. L. Strategies for Reducing Leprosy Stigma Mycobacterial Diseases. 8, (2018).

13. Dadun et al. Exploring the Complexities of Leprosy-related Stigma and the Potential of a Socio-economic Intervention in a Public Health Context in Indonesia. Asia Pacific Disabil. Rehabil. J. 27, 5-23 (2016).

14. Van'T Noordende, A. T., Van Brakel, W. H., Banstola, N. \& Dhakal, K. P. The impact of leprosy on marital relationships and sexual health among married women in eastern Nepal. J. Trop. Med. 2016, (2016).

15. Somar, P., Waltz, M. \& van Brakel, W. The impact of leprosy on the mental wellbeing of leprosy-affected persons and their family members - a systematic review. Glob. Ment. Heal. 7, (2020).

16. Loh, J. M. I., Schutte, N. S. \& Thorsteinsson, E. B. Be Happy: The Role of Resilience Between Characteristic Affect and Symptoms of Depression. 1125-1138 (2014) doi:10.1007/s10902-013-9467-2.

17. Cummins, R. A. \& Wooden, M. Personal Resilience in Times of Crisis: The Implications. 223-235 (2014) doi:10.1007/s10902-013-9481-4.

18. Collazzoni, A. et al. Resilience as a Mediator Between Interpersonal Risk Factors and Hopelessness in Depression. Front. Psychiatry 11, 1-7 (2020).

19. Salguero, A. \& RuI, R. Relationship Between Resilience and Coping Strategies in Competitive Sport. Percept. Mot. Skills (2016) doi:10.1177/0031512516631056.

20. Labrague, L. J. Psychological resilience, coping behaviours and social support among health care workers during the COVID- 19 pandemic : A systematic review of quantitative studies. J. Nurs. Manag. (2021) doi:10.1111/jonm.13336.

21. Macía, P., Barranco, M., Gorbeña, S., Álvarez-Fuentes, E. \& Iraurgi, I. Resilience and coping strategies in relation to mental health outcomes in people with cancer. PLoS One 16, e0252075 (2021).

22. Ye, Z. et al. Resilience, Social Support, and Coping as Mediators between COVID-19-related Stressful Experiences and Acute Stress Disorder among College Students in China. Appl. Psychol. Heal. Well-Being 12, 1074-1094 (2020).

23. Carpenter, A. Resilience in the social and physical realms: Lessons from the Gulf Coast. Int. J. Disaster Risk Reduct. 14, (2014).

24. Hopkins, K. D., Shepherd, C. C. J. \& Taylor, C. L. Relationships between Psychosocial Resilience and Physical Health Status of Western Australian Urban Aboriginal Youth. PLoS One 1-16 (2015) doi:10.1371/journal.pone.0145382.

25. Callan, V. J., Terry, D. J. \& Schweitzer, R. Coping resources, coping strategies and adjustment to organizational change : Direct or buffering effects ? Empl. Adjust. to Organ. Chang. 8, 372-383 (1994).

26. Raedeke, T. D. \& Smith, A. L. Coping Resources and Athlete Burnout: An Examination of Stress Mediated and Moderation Hypotheses. J. Sport Exerc. Psychol. 1-130 (2005) doi:10.4324/9780203976272.

27. Matheny, K. B., Roque-Tovar, B. E. \& Curlette, W. L. Perceived stress, coping resources, and life satisfaction among U. S. and Mexican college students: A cross-cultural study. An. Psicol. 24, 49-57 (2008).

28. Rabenu, E. \& Yaniv, E. Psychological Resources and Strategies to Cope with Stress at Work. 10, 8-15 (2017). 
29. Mak, A. S. Korean International Students' Coping Resources and Psychological Adjustment in Australia. Omnes 2, (2011).

30. Matheny, K. B. et al. Coping Resources, Perceived Stress, and Life Satisfaction Among Turkish and American University Students. Int. J. Stress Manag. 9, 81-97 (2002).

31. Wood, A. M., Joseph, S. \& Linley, P. A. Coping style as a psychological resource of grateful people. J. Soc. Clin. Psychol. 26, 1076-1093 (2007).

32. Finkelstein-fox, L. \& Park, C. L. Control-Coping Goodness-of-Fit and Chronic Illness: A Systematic Review of the Literature. Health Psychol. Rev. 0, 1-58 (2018).

33. Petrie, K. J. \& Jones, A. S. K. Coping with chronic illness. in The Cambridge handbook of psychology, health and medicine, 3rd ed. 110-114 (Cambridge University Press, 2019).

34. Helgeson, V. S. \& Zajdel, M. Adjusting to Chronic Health Conditions. (2017) doi:10.1146/annurev-psych010416-044014.

35. Schulz, M. S. \& Allen, R. A. Psychological adjustment after breast cancer: A systematic review of longitudinal studies. (2012) doi:10.1002/pon.4230.

36. Whittemore, R. \& Dixon, J. Chronic illness: the process of integration. 177-187 (2008) doi:10.1111/j.13652702.2007.02244.x.

37. Whitehead, L., Elisabeth, J. \& Amanda, T. The role of the family in supporting the self -management of chronic conditions: A qualitative systematic review. 0-2 (2017) doi:10.1111/ijlh.12426.

38. Zeligman, M., Varney, M., Grad, R. I. \& Huffstead, M. Posttraumatic Growth in Individuals With Chronic IIIness: The Role of Social Support and Meaning Making. 96, 53-63 (2018).

39. Warner, C. B., Restorick, A., Jeanblanc, A. B. \& Adams, K. B. Coping Resources, Loneliness, and Depressive Symptoms of Older Women With Chronic Illness. (2019) doi:10.1177/0733464816687218.

40. Compas, B. E., Jaser, S. S., Dunn, M. J. \& Rodriguez, E. M. Coping with Chronic Illness in Childhood and Adolescence. Annu. Rev. Clin. Psychol. 8, 455-480 (2012).

41. Taylor, S. E. \& Stanton, A. L. Coping Resources, Coping Processes, and Mental Health. Annu. Rev. Clin. Psychol. 3, 377-401 (2007).

42. Sermrittirong, S. \& Brakel, W. H. Van. Stigma in leprosy: concepts, causes and determinants. (2014) doi:10.47276/Ir.85.1.36.

43. Marahatta, S. B. et al. Perceived stigma of leprosy among community members and health care providers in Lalitpur district of Nepal: A qualitative study. PLoS One 13, 1-13 (2018).

44. de Souza, C. D. F. et al. Physical disabilities due to leprosy in alagoas state, northeast brazil: A temporal and spatial modeling. Rev. Soc. Bras. Med. Trop. 52, 0-1 (2019).

45. Susanti, I. A. et al. Social stigma, adherence to medication and motivation for healing: A cross-sectional study of leprosy patients at Jember Public Health Center, Indonesia. J. Taibah Univ. Med. Sci. 13, 97-102 (2018).

46. Hamim, N., Mariani, M. \& Sismulyanto, S. Social Care in Improving Self-Concept of Leprosy Patients. J. Ners 15, 37-41 (2020).

47. Van, A. T., Id, N., Wubie, M., Id, A. \& Tadesse, T. A family-based intervention for prevention and selfmanagement of disabilities due to leprosy, podoconiosis and lymphatic filariasis in Ethiopia : A proof of concept study. 215, 1-18 (2021). 
48. Heijnders, M. L. Experiencing leprosy: Perceiving and coping with leprosy and its treatment. A qualitative study conducted in Nepal. Lepr. Rev. 75, 327-337 (2004).

49. Noordende, A. T. van't, Pereira, Z. B. da S. \& Kuipers, P. Key sources of strength and resilience for persons receiving services for Hansen 's disease (leprosy) in Porto Velho, Brazil : What can we learn for service development ? Int. Health 1-9 (2021) doi:10.1093/inthealth/ihab001.

50. Anderson, J. C. \& Gerbing, D. W. Structural Equation Modeling in Practice: A Review and Recommended TwoStep Approach. Psychol. Bull. 103, 411-423 (1988).

51. Hu, L. \& Bentler, P. M. Cutoff criteria for fit indexes in covariance structure analysis: Conventional criteria versus new alternatives. Struct. Equ. Model. 6, 1-55 (1999).

52. Krabbe, P. F. M. Validity. Meas. Heal. Heal. Status 113-134 (2017) doi:10.1016/b978-0-12-801504-9.00007-6.

53. Mavridis, D., Moustaki, I. \& Knott, M. Goodness-of-Fit Measures for Latent Variable Models for Binary Data. Handbook of Latent Variable and Related Models vol. 1 (Elsevier B.V., 2007).

54. Martin, R. D., Gomez, I. F. \& Spies, L. A. Burden of Leprosy. J. Nurse Pract. 13, 538-545 (2017).

55. Adolphs, R. The Biology of Fear. 23, (2014).

56. Yusuf, A., Aditya, R. S., Yunitasari, E., Aziz, A. N. \& Solikhah, F. K. Experience of Persons Affected by Leprosy in Facing Psychosocial Problems: A Qualitative Method. 11, 219-223 (2020).

57. Nasir, A., Yusuf, A., Listiawan, M. Y., Harianto, S. \& Huda, N. Adaptive Strategy of Women`s Leprosy in Indonesia Psychic Experience of Women with Leprosy in Living a Community Life. 11, 306-312 (2020).

58. Wu, Y., Sang, Z. Q., Zhang, X. C. \& Margraf, J. The Relationship Between Resilience and Mental Health in Chinese College Students: A Longitudinal Cross-Lagged Analysis. Front. Psychol. 11, (2020).

59. Rahimi, B., Baetz, M., Bowen, R. \& Balbuena, L. Resilience, stress, and coping among Canadian medical students. Can. Med. Educ. J. 5, (2014).

60. Zhang, J. et al. The Coexistence of Coping Resources and Specific Coping Styles in Stress: Evidence from Full Information Item Bifactor Analysis. 9, (2014).

61. Adhikari, B., Kaehler, N., Chapman, R. S., Raut, S. \& Roche, P. Factors Affecting Perceived Stigma in Leprosy Affected Persons in Western Nepal. PLoS Negl. Trop. Dis. 8, 2-9 (2014).

62. Tugade, M. M. \& Fredrickson, B. L. Regulation of positive emotions: emotion regulation strategies that promote resilience. 311-333 (2007) doi:10.1007/s10902-006-9015-4.

63. Ramos, E., Arantzazu, D., Fernández, R. \& Axpe, I. Perceived Emotional Intelligence and Life Satisfaction Among Adolescent Students: The Mediating Role of Resilience. J. Happiness Stud. 20, 2489-2506 (2019).

64. Zimmer-Gembeck, M. J. \& Skinner, E. A. The Development of Coping: Implications for Psychopathology and Resilience AS INDIVIDUAL DIFFERENCES IN APPRAISAL. Wiley Online Libr. (2016) doi:https://doi.org/10.1002/9781119125556.devpsy410.

65. Guruprakash, K. V et al. A study of relationship between perceived stress, coping pattern, burnout, and general psychopathology among the postgraduate medical students. Ind. Psychiatry J. 27, 141-146 (2018).

66. Van, A. T. et al. Strengthening individual and family resilience against leprosy-related discrimination: A pilot intervention study. PLoS Negl. Trop. Dis. 1-16 (2021) doi:10.1371/journal.pntd.0009329.

67. Weinberg, M., Tomyn, A. J. \& Weinberg, M. K. Resilience and Subjective Wellbeing: A Psychometric Evaluation in Young Australian Adults : Resilience and subjective wellbeing Resilience and Subjective Wellbeing : A Psychometric Evaluation in Young Australian Adults. Aust. Psychol. (2018) doi:10.1111/ap.12251. 
68. Zheng, W. \& Huang, A. Y. Mediating effects of psychological resilience on life satisfaction among older adults: A cross-sectional study in China. 1-10 (2020) doi:10.1111/hsc.12965.

69. Abolghasemi, A. \& Varaniyab, S. T. Resilience and perceived stress: predictors of life satisfaction in the students of success and failure. Procedia Soc. Behav. Sci. 5, 748-752 (2010).

70. Govindasamy, K., Jacob, I., Solomon, R. M. \& Darlong, J. Burden of depression and anxiety among leprosy affected and associated factors - A cross sectional study from India. 1-12 (2021) doi:10.1371/journal.pntd.0009030.

71. Halford, J. \& Brown, T. Cognitive-behavioural therapy as an adjunctive treatment in chronic physical illness. Adv. Psychiatr. Treat. 15, 306-317 (2009).

72. Taylor, S. E. \& Stanton, A. L. Coping Resources, Coping Processes, and Mental Health. 377-401 (2007) doi:10.1146/annurev.clinpsy.3.022806.091520.

73. Van'T Noordende, A. T., Kuipers, P. \& Pereira, Z. B. S. Strengthening personal and family resilience: a literature review for the leprosy context. Lepr. Rev. 90, 88-104 (2019).

74. Rueda, B. \& Valls, E. Is the Effect of Psychological Inflexibility on Symptoms and Quality of Life Mediated by Coping Strategies in Patients with Mental Disorders ? (2020).

75. Vulpe, A. \& Dafinoiu, I. Positive emotions, coping strategies and ego-resiliency : A mediation model. Procedia Soc. Behav. Sci. 33, (2012).

76. Chiang, C.-Y. \& Hsu, H.-L. Effectiveness of a Mind Training and Positive Psychology Program on Coping Skills in School Children in Taiwan. J. Child Adolesc. Behav. 03, (2015).

77. Wu, Y. et al. Psychological resilience and positive coping styles among Chinese undergraduate students: a cross-sectional study. BMC Psychol. 1-11 (2020).

78. Taylor, S. E. \& Stanton, A. L. Coping Resources, Coping Processes, and Mental Health. Annu. Rev. Clin. Psychol. 3, 377-401 (2007). 